\title{
Socio-demographic determinants of teenage pregnancy in the Niger Delta of Nigeria
}

\author{
Ayuba Ibrahim Isa ${ }^{*}$, Ibukun Olugbenga Owoeye Gani ${ }^{2}$ \\ ${ }^{1}$ Department of Obstetrics and Gynaecology, College of Health Sciences, Niger Delta University, Amassoma, Nigeria \\ ${ }^{2}$ Department of Community Medicine, College of Health Sciences, Niger Delta Unversity, Amassoma, Nigeria \\ Email: daddayzee@yahoo.com
}

Received 27 April 2012; revised 30 May 2012; accepted 13 June 2012

\section{ABSTRACT}

Sub-Saharan Africa has the highest rates of maternal and neonatal mortality worldwide. Young maternal age at delivery has been proposed as risk factor for adverse pregnancy outcome, it occurs in all races, faiths, socioeconomic statuses, and regions. Teenage mothers are likely to be unmarried, poor and to sacrifice education. Isolation, unstable marriages, stress, and guilt are among many social and psychological problems. The aim of this study is to determine the socio-demographic factors associated with teenage pregnancy in our environment, in order to proffer measures that can help curtail this continuing sociomedical problem. The records of all teenage mothers (aged 13 - 19) who had delivery at the Niger Delta University Teaching Hospital, Bayelsa State, Nigeria, over a period of 4 years (January 12007 to December 31 2010) were retrospectively reviewed. There were a total of 1341 deliveries during the study period, out which 83 were teenagers giving an incidence of $6.2 \%$. The age of the patients ranged from 14 to 19 years with a mean age of $(28.1 \pm 5.7)$ years. Their parity ranged from zero to three, with a mean of $2.4 \pm 1.9$. About a third (20\%/24.1\%) were primigravidae, 33\%/ $39.9 \%$ had at least secondary education and majority (48\%/57.8\%) were unbooked, unmarried (60\%/72.3\%), unemployed $(62 \% / 74.7 \%)$ and of low social class. Majority 71 (85.5\%) of the teenage mothers had never used any form of modern contraceptive method and $45(54.2 \%)$ of them had terminated at least one pregnancy in the past. 26 (31.3\%) had Caesarean sections, majority of which were emergencies 22 (84.6\%). It was concluded that teenage mothers in the Niger Delta tend to have unfavorable socio-demographic and obstetric factors. Concrete measures must be put in place to address these.

Keywords: Teenage Pregnancy; Socio-Demographic

\footnotetext{
"Corresponding author.
}

Factors; Niger Delta

\section{INTRODUCTION}

Adolescence, according to WHO refers to the period between the ages of 10 and 19 years in which the individual progresses from the initial appearances of secondary sexual characteristics to full sexual maturity and during which psychological and emotional processes develop from those of a child to those of an adult. It also represents a transition from the state of socio-economic dependence to one of relative independence $[1,2]$.

Adolescent pregnancy is defined as gestation in women before having reached the full somatic development. The percentage of childbearing adolescent women is regionally highly variable depending on cultural, religious, political, economic and other factors. Pregnancy in the very young is generally considered to be a high risk event because of the additional burden imposed by reproduction on a still growing body [3-5].

Large epidemiologic studies on this topic were however largely reported from high or medium income countries showing conflicting results. Most importantly to date there is a lack of epidemiologic evidence from SubSaharan Africa [6-10].

Most of the pregnancies result from coitus with their first only partner, who often times is of similar age and no more advantaged socially. Adolescent pregnancies constitute major socio-medical and socio-economic problems in both developed and developing countries and are becoming more prevalent in recent times [11].

The emergence of this adolescent problem has been attributed to various factors including early marriage, social permissiveness favouring early exposure to casual sexual activity, poor knowledge, availability and use of contraceptives, maternal deprivation, pre-existing psychosocial problems in the family and general non-functioning family unit among others [12-14].

In many developing countries, lack of resources makes contraception and reproductive advice inaccessible. This 
situation may be exacerbated by religious beliefs that disapprove of artificial birth control methods. The result is that many adolescents, both married and unmarried find it difficult to locate, or even seek help about sexual matters. There may be few facilities offering such support, particularly in remote rural areas. The poorest often lack the resources to travel to these facilities and any fees charged for the services on offer would push them even further out of reach. In some cases, the ante-natal clinic is the only place where a young woman can obtain reproductive advice, but pregnancy is a pre-condition. Contraception may not be offered to married women until they have borne a child. There is an urgent need for "youth friendly" health services, as adolescents are unlikely to seek help about sexual matters from a service that is unsympathetic to their needs and anxieties. Girls aged 15 to 19 give birth to 15 million baby a year. Many of these girls give birth without attending an antenatal clinic or receiving the help of a professional midwife. It is essential to devise programs to reach girls in and out of marriage with reproductive advice and services [15].

Complications seen in adolescents during pregnancy include anaemia from malaria, infection and inadequate nutrition, spontaneous abortions, preterm labour and delivery, pre-eclampsia and eclampsia, antepartium haemorrhage and feto pelvic disproportion with its attendant risks of high operative intervention rates, obstructed labour and its sequalae notably genital fistulae. In the puerperium, puerperal sepsis, anaemia and other complications resulting from obstructed labour are common [16, 17]. Evidence shows that infant mortality among the children is sometimes two times higher than among those of old peers. A stronger likelihood of low birth-weight in the infant has been recorded among adolescent mothers than among older peers. This is mainly associated with poor maternal nutrition. Low birth-weight babies are 5 30 times more likely to die than babies of normal weight $[18,19]$. If a mother is under 18 , her baby's chance of dying in the first year of life is 60 per cent higher than that of a baby born to a mother older than 19. Part of this heavy toll has more to do with poor socio-economic status and lack of ante-natal and obstetric care than physical maturity alone [20].

Cervical carcinoma, which is increasing in incidence and presenting at a younger age, is directly linked to the age of first intercourse and to the number of partners, and the spread of infection by human immunodeficiency virus (HIV) is also linked to the number of sexual partners. These medical problems emphasize the risks associated with teenage intercourse, particularly if with a number of partners, in addition to the risks of the pregnancy itself. Pregnancy-related deaths are the leading cause of mortality for 15 - 19 year-old girls (married and unmarried) worldwide. Mothers in this age group face a 20 to 200 per cent greater chance of dying in pregnancy than women aged 20 to 24 [21]. The socio-economic consequences of adolescent pregnancy include more unwanted pregnancies and out-of-wedlock children, greater marital instability, poor education, fewer assets and lower income later in life. The problems associated with adolescent pregnancy can be significantly reduced through sex education, provision of contraceptive counseling and services, education of women up to the University level and medical, social and psychological support for affected adolescents. Provision of good antenatal, intranatal and postnatal care for these adolescents is also emphasized [22,23].

\section{MATERIALS AND METHODS}

The study is a four year retrospective study of Teenage pregnancies managed at Niger Delta University Teaching Hospital (NDUTH) Okolobiri, a tertiary hospital in Bayelsa State, from January 1, 2007 to December 31, 2010. The sources of information were Antenatal, labour, and neonatal ward records, theater records, patient's records and case notes. The information obtained were coded and transferred onto a profoma already design for the study.

Variables relating to the socio demographic characteristics of the women, antenatal and intrapartum complications and neonatal outcome were obtained. Statistical Analysis: Statistical analysis was performed with Statistical Package for Social Sciences (SPSS version 10).

Ethical Consideration: Approval for this work was given by the Ethical Committee of the NDUTH.

\section{RESULTS}

There were a total of 1341 deliveries, during the study period, out which 83 were teenagers (6.2\%).

The age of the patients ranged from 14 to 19 years with a mean age of $(28.1 \pm 5.7)$ years. Their parity ranged from zero to three, with a mean of $2.4 \pm 1.9$. About a third 20 (24.1\%) were primigravidae, 33 (39.9\%) had at least secondary education and majority 48 (57.8\%) were unbooked and unmarried 60 (72.3\%) (Table 1).

Majority of the patients were of low social class, only 1 (4.3\%) patient is of social class one (Table 2).

The three commonest complications are preterm labour $(51.8 \%)$, postpartum haemmorrhage $(34.9 \%)$ and anaemia in pregnancy (22.9\%) (Table 3).

$26(31.3 \%)$ of the teenage mothers delivered by caesarean section, $(p=0.014)$ majority of which were emergencies 22 (84.6\%), 55 (66.2\%) had spontaneous vaginal delivery, while $2(2.5 \%)$ had instrumental vaginal delivery (Table 4).

There were 11 perinatal deaths with a perinatal mortality rate of 133/1000. There was no maternal mortality. 
Table 1. Socio-demographic characteristics of the patients.

\begin{tabular}{|c|c|}
\hline Characteristics & Teenage Mothers Freq (\%) \\
\hline \multicolumn{2}{|l|}{ Age (years) } \\
\hline $14-16$ & $20(24.1)$ \\
\hline $17-19$ & $63(75.9)$ \\
\hline Total & $83(100)$ \\
\hline $\mathrm{X}+\mathrm{SD}$ & $17.8+1.3$ \\
\hline \multirow[t]{2}{*}{$95 \%$ CI } & $17.5-18.1$ \\
\hline & $\mathrm{t}=24.25$ \\
\hline \multicolumn{2}{|l|}{ Parity } \\
\hline 0 & $20(24.1)$ \\
\hline $1-3$ & $63(75.9)$ \\
\hline $4-7$ & $0(0)$ \\
\hline$>7$ & $0(0)$ \\
\hline Total & $83(100)$ \\
\hline$x^{2}=$ & 55.37 \\
\hline \multicolumn{2}{|l|}{ Educational Status } \\
\hline Nil & 19 (22.9) \\
\hline Primary & $26(31.1)$ \\
\hline Secondary & 33 (39.9) \\
\hline Tertiary & $5(6.1)$ \\
\hline Total & $83(100)$ \\
\hline$x^{2}=$ & 16.29 \\
\hline \multicolumn{2}{|l|}{ Booking Status } \\
\hline Booked & $35(42.2)$ \\
\hline Unbooked & $48(57.8)$ \\
\hline Total & $83(100)$ \\
\hline$x^{2}=$ & 17.74 \\
\hline \multicolumn{2}{|l|}{ Marital Status } \\
\hline Married & $23(27.7)$ \\
\hline Not Married & $60(72.3)$ \\
\hline Total & $83(100)$ \\
\hline$x^{2}=$ & 27.2 \\
\hline
\end{tabular}

\section{DISCUSSION}

The frequency of pregnancy during adolescence is highly variable in Africa [8-10]. Cultural and religious norms may be one of the reasons for these demographic differences. In addition, these cultural factors may modify
Table 2. Social class of patients with teenage pregnancy at niger delta university teaching hospital (nduth) okolobiri (20072010).

\begin{tabular}{cc}
\hline Social Class & Frequency \\
\hline I & $1(4.3)$ \\
II & $3(13.1)$ \\
III & $4(17.4)$ \\
IV & $7(30.4)$ \\
V & $8(34.8)$ \\
Total & $\mathbf{2 3 ( 1 0 0 )}$ \\
\hline
\end{tabular}

Table 3. Pregnancy complications in teenage mothers.

\begin{tabular}{cc}
\hline Complication & Teenage Mothers n = 83 Freq (\%) \\
\hline Iron Deficiency Anaemia & $19(22.9 \%)$ \\
Preeclampsia & $12(14.5 \%)$ \\
Aproptio Placenta & $5(6.0 \%)$ \\
Placenta Praevia & $0(0 \%)$ \\
Preterm Labour & $43(51.8 \%)$ \\
Postpartum Haemorrhage & $29(34.9 \%)$ \\
\hline
\end{tabular}

Table 4. Route of delivery.

\begin{tabular}{cc}
\hline & Teenage Mothers n = 83 Freq (\%) \\
\hline Spontaneous Vaginal Delivery & $55(66.2)$ \\
Instrumental Delivery & $2(2.4)$ \\
Caesarean Section & $26(31.3)$ \\
Emergency & $22(84.6)$ \\
Elective & $4(15.4)$ \\
\hline
\end{tabular}

health care seeking behavior of young pregnant women and may therefore constitute by themselves confounding factors for pregnancy outcome as only $6.2 \%$ of the parturient are teenagers in this study, which is lower than $9 \%$ from Thailand, but higher than $1.7 \%$, and $2.2 \%$ from Benin and Ibadan in Nigeria respectively [22,23].

The review also revealed that, marital status, educational qualification and unemployment are important socio-demographic factors contributing to teenage pregnancy, furthermore, majority of the patients were of low social class. The social class of the patients were determine using the summation of the score obtained from the educational status of the women and the occupation of their husbands [24].

Majority of them were single, unemployed, unbooked with less formal education. This is similar to the finding 
from the same region [23]. In a study from Zimbabwe, transport costs and costs for prenatal services have been characterized as major factors influencing adolescents late or non-utilization of prenatal services. In the same study the limited knowledge of young women about antenatal care programs and the fear of HIV testing have been further obstacles to efficient antenatal care [25].

Contraceptive utilization among the patients showed that $85.5 \%$ had never used any form of contraceptive. Other studies had shown that only $3 \%-5 \%$ of married couples use a modern contraceptive method and $2 \%$ to $6 \%$ of the sexually active adolescents practice any form of contraception [26].

In Nigeria, family planning services are few and providers tend to ignore or discriminate against single adolescents. 54.2\% had the history of at least one previous termination of pregnancy. This finding is not surprising because of the significantly low prevalence of contraceptive usage in our communities [26].

Anaemia in pregnancy, preeclampsia, preterm labour, and postpartum haemmoraghe, were some of the obstetrics Complications documented among the teenagers seen in this review. This is similar to findings from previous studies [5,23] most of these patients were referred from private and public primary and secondary health facilities both within and sometimes outside Bayelsa state.

Several reasons for the high risk of delivering a low birth weight infant by adolescent mothers have been discussed in scientific literature. Anatomic immaturity and continued maternal growth may represent biologic growth barriers for the fetus. Moreover, adolescent mothers may represent a particularly disadvantaged risk group characterized by low socioeconomic status, financial income and level of education as was found from this study $[3,11,20]$.

Vaginal delivery was the major route of delivery in the study group (66.2\%), however, 31.3\% had Caesarean section, of which $84.6 \%$ were emergencies, often times, and they had been in labour for more than 24 hours at other centres and often referred late in the night with varied reasons. This is the main reason why emergency procedures accounted for a larger proportion of the cases. This is similar to findings from previous studies $[5,23]$.

In conclusion the socio-demographic factors and the medical problems associated with teenage pregnancy have been amply documented in this country and also by this study. Amidst the poorer social segments parenthood is seen as a sign of social status; however it is associated with adverse fetal and maternal outcomes. The adverse outcomes can be ameliorated by free and compulsory education for the girl child, education of the populace about the social and medical consequences of teenage pregnancy, making contraceptives available to teens, especially emergency contraceptives, quality antenatal care, and provision of essential obstetric care.

\section{REFERENCES}

[1] World Health Organization (1981). Report of a WHO meeting on adolescent sexuality and reproductive health. 21-23.

[2] Sai, T.F. (2006) Adolescent sexuality and reproductive health. In: Mati, J.K.G., Ladipo, A. O, Burleman, R.T., et al, Eds., Reproductive health in Africa, John Hopkins' Programme for International Education in Gynaecology and Obstetrics, Bangkok, 16-30.

[3] Scholl, T.O., Hediger, M.L., Salmon, R.W., Belsky, D.H. and Ances, I.G. (1989). Association between gynecological age and preterm birth. Paediatric and Perinatal Epidemiology, 3, 357-366. doi:10.1111/j.1365-3016.1989.tb00524.x

[4] Paranjothy, S., Broughton, H., Adappa, R. and Fone, D. (2008) Teenage pregnancy: Who suffers? Archives of Disease in Childhood, 94, 239-245. doi:10.1136/adc.2007.115915

[5] Bacci, A., Manhica, G.M., Machungo, F., Bugalho, A. and Cuttini, M. (1993) Outcome of teenage pregnancy in Maputo, Mozambique. International Journal of Gynaecology \& Obstetrics, 40, 19-23. doi:10.1016/0020-7292(93)90767-Q

[6] Chen, X., Wen, S.W., Fleming, N., et al. (2007) Teenage pregnancy and adverse birth outcomes: A large population based retrospective cohort study. International Journal of Epidemiology, 36, 368-373. doi:10.1093/ije/dyl284

[7] Kramer, M.S. (1987) Determinants of low birth weight: Methodological assessment and meta-analysis. Bulletin of the World Health Organization, 65, 663-737.

[8] Adam, I., Babiker, S., Mohmmed, A.A., et al. (2007) Low body mass index, anaemia and poor perinatal outcome in a rural hospital in eastern Sudan. Journal of Tropical Pediatrics, 54, 202-204.

[9] Feresu, S.A., Harlow, S.D., Welch, K. and Gillespie, B.W. (2004) Incidence of and socio-demographic risk factors for stillbirth, preterm birth and low birthweight among Zimbabwean women. Paediatric and Perinatal Epidemiology, 18, 154-163. doi:10.1111/j.1365-3016.2003.00539.x

[10] Elshibly, A.M. and Schmalisch, G. (2008) The effect of maternal anthropometric characteristics and social factors on gestational age and birth weight in Sudanese newborn infants. BMC Public Health, 8, 244. doi:10.1186/1471-2458-8-244

[11] Okpani, A.O.U., Ikimalo, J., John, C.T and Briggs, N.D. (1995) Teenage pregnancy. Tropical Journal of Obstetrics and Gynaecology, 12, 34-36.

[12] Aboyeji, A. F. (1997) Obstetric performance of teenage primigraridae in Ilorin, Nigeria. Nigeria Medical Journal, 33, 56-59.

[13] Beazley, J.M. (1996) Special circumstances affecting labour. In: Whitefield, C.R., Ed., Dewhurst's textbook of 
obstetrics and gynaecology for postgraduates, 5th Edition, 312-313.

[14] Romans, S.E., Martins, J.H. and Morries, E.M. (1997) Risk factors for adolescent pregnancy: How important is child abuse? Otago women's health study. The New Zealand Medical Journal, 110, 30-33.

[15] Rao Gupta, G. (1998), Claiming the future. Progress of Nations UNICEF, 12-13.

[16] Ojengbede, O.A., Otolorin, E.O. and Fabanwo, W.O. (1987) Pregnancy performance of Nigerian women aged 16 years and below seen in Ibadan, Nigeria. African Journal of Medicine and Medical Sciences, 16, 89-95.

[17] United Nations (1989) Adolescent reproductive behavior: Evidence from developing countries, Vol. II. UN Population Studies, New York.

[18] Second World Situation Report (1992) ACC/SCN, Geneva, 17.

[19] UNICEF (1994) Too old for toys, too young for motherhood. United Nations Children's Fund, New York, 23-25.

[20] Curtis, H.A., Lawrence, C.J and Tripp, J.H. (1988) Teenage sexual intercourse and pregnancy. Archives of Disease in Childhood, 63, 373-379. doi:10.1136/adc.63.4.373

[21] Watcharaseranee, N., Pinchantra, P. and Piyaman, S.
(2006) The incidence and complications of teenage pregnancy at Chonburi Hospital. Journal of Medical Association of Thailand, 4, 118-123.

[22] Ebeigbe, P.N. and Gharoro, E.P. (2007) Obstetric complications, intervention rates and maternofetal outcome in teenage nullipara in Benin City, Nigeria. Tropical Doctor, 37, 79-83. doi:10.1258/004947507780609356

[23] Adeyinka, D.A., Oladimeji, O., Adekanbi, T.I., Adeyinka, F.E., Falope, Y. and Aimakhu, C. (2010) Outcome of adolescent pregnancies in southwestern Nigeria: A case-con- trol study. Journal of Maternal-Fetal \& Neonatal Medicine, $\quad$ 8, 785-789. doi:10.3109/14767050903572166

[24] Olusanya, O., Okpere, E.E. and Ezimokhai, M. (1985) The importance of social class in voluntary fertility control in a developing country. West African Journal of Medicine, 4, 205-207.

[25] Chaibva, C.N., Ehlers, V.J. and Roos, J.H. (2009) Midwives' perceptions about adolescents' utilization of public prenatal services in Bulawayo, Zimbabwe. Midwivery, 10, 116-118.

[26] Ibrahim, M.I. and Okolo, R.U. (1997) Profile of contraceptive acceptors in UDUTH, Sokoto, Nigeria. Nigeria Medical Practitioner, 13, 9-13. 